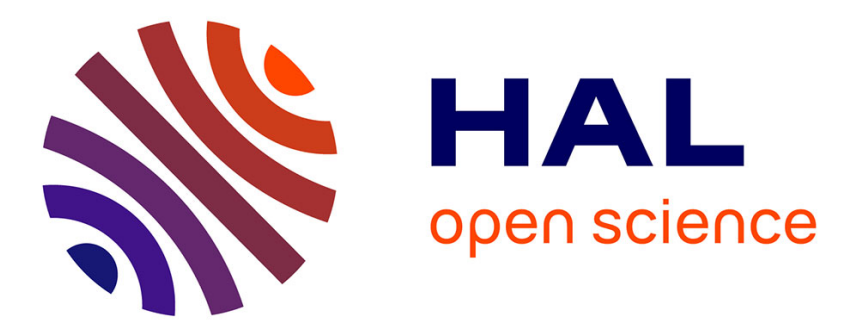

\title{
Tunable hydrogen release from amine-boranes via their insertion into functional polystyrenes
}

\author{
Juliette Brunet, Audrey Ledoux, Emmanuel Lacôte, Jean Raynaud
}

\section{To cite this version:}

Juliette Brunet, Audrey Ledoux, Emmanuel Lacôte, Jean Raynaud. Tunable hydrogen release from amine-boranes via their insertion into functional polystyrenes. Angewandte Chemie International Edition, 2019, 10.1002/anie.201904898 . hal-02264588

\section{HAL Id: hal-02264588 \\ https://univ-lyon1.hal.science/hal-02264588}

Submitted on 7 Aug 2019

HAL is a multi-disciplinary open access archive for the deposit and dissemination of scientific research documents, whether they are published or not. The documents may come from teaching and research institutions in France or abroad, or from public or private research centers.
L'archive ouverte pluridisciplinaire HAL, est destinée au dépôt et à la diffusion de documents scientifiques de niveau recherche, publiés ou non, émanant des établissements d'enseignement et de recherche français ou étrangers, des laboratoires publics ou privés. 


\title{
Tunable hydrogen release from amine-boranes via their insertion into functional polystyrenes
}

\author{
Audrey Ledoux, ${ }^{[a]}$ Jean Raynaud, ${ }^{[a], *}$ Emmanuel Lacôte ${ }^{[b], *}$
}

\begin{abstract}
Polystyrene-g-boramines random copolymers are dihydrogen reservoirs with tunable dehydrogenation temperatures, which can be adjusted by selecting the boramine content in the copolymers. They display a unique dihydrogen thermal release profile, which is a direct consequence of the insertion of the amineboranes in a polymeric scaffold, and not from a direct modification of the electronics or sterics of the amine-borane function. Finally, the mixture of polystyrene-g-boramines with conventional $\mathrm{NH}_{3}-\mathrm{BH}_{3}$ (borazane) allows for a direct access to organic/inorganic hybrid dihydrogen reservoirs with a maximal $\mathrm{H}_{2}$ loading of $8 \mathrm{wt} \%$. These exhibit a dehydrogenation temperature lower than that of either the borazane or the polystyrene-g-boramines taken separately.
\end{abstract}

The storage of quickly releasable dihydrogen in dense reservoirs is an important challenge. On a large scale, this would help transition to hydrogen-based clean fuels. On a smaller scale, a portable source of dihydrogen would enable emergency power generation or could be used for chemical reactions. Borazane $\left(\mathrm{NH}_{3}-\mathrm{BH}_{3}\right)$ was early on identified as a strong contender for a chemical $\mathrm{H}_{2}$ reservoir, due to its density and high hydrogen content,[1] for which catalytic dehydrogenation methods have been devised.[2] However, as a fluffy solid, it is poorly processable; dehydrogenation is not selective in the absence of a catalyst and requires thermal activation at temperature both too high for fuel cells and too low for long-term storage; the $\mathrm{H}_{2}$ harvest is often incomplete; the $\mathrm{H}_{2}$ released is contaminated with corrosive volatile byproducts.[3]

To tune the physical state or the dehydrogenation temperature, without lowering too much the $\mathrm{H}_{2}$ content of the proposed fuels, research has focused on alternative amine-borane molecules with modified substituents, at the $N$ and/or the $B$ end.[1,4] We approached the processability problem from another angle, choosing to insert the amine-borane motif into a polymer scaffold. Our initial strategy was to use the amine-borane function in the main polymer chain of polyboramines (Figure 1, center).[5] In stark difference from their molecular analogues, the polymers dehydrogenated thermally below $100^{\circ} \mathrm{C}$, in an overall entropy-driven endothermic process. The increased presence of catalytic borane chain-ends due to Lewis pair partial

[a] A. Ledoux, Dr. J. Raynaud

Univ Lyon, Univ Claude Bernard Lyon 1, CPE Lyon, CNRS, C2P2 43 Bd du 11 novembre 1918, F-69616 Villeurbanne, France E-mail: jean.raynaud@univ-lyon1.fr

[b] Dr. E Lacôte

Univ Lyon, Univ Claude Bernard Lyon 1, CNRS, CNES, ArianeGroup, LHCEP

Bât. Raulin, 2 rue Victor Grignard, F-69622 Villeurbanne, France E-mail: emmanuel.lacote@univ-lyon1.fr

Supporting information for this article is given via a link at the end of the document.((Please delete this text if not appropriate)) dissociations in the mechanically stressed polyboramines likely provide a catalyst for the dehydrogenation.

We now introduce new $\mathrm{H}_{2}$-rich amine-borane polymers. The key Lewis-paired amine-boranes are introduced post-synthetically onto the side chains of polystyrene random copolymers that can be synthesized by simple radical copolymerization of a boronate-functionalized styrene and styrene (Figure 1, right).[6] We show that the dehydrogenation temperature can be dialed in upon simply choosing the ratio of co-monomers.

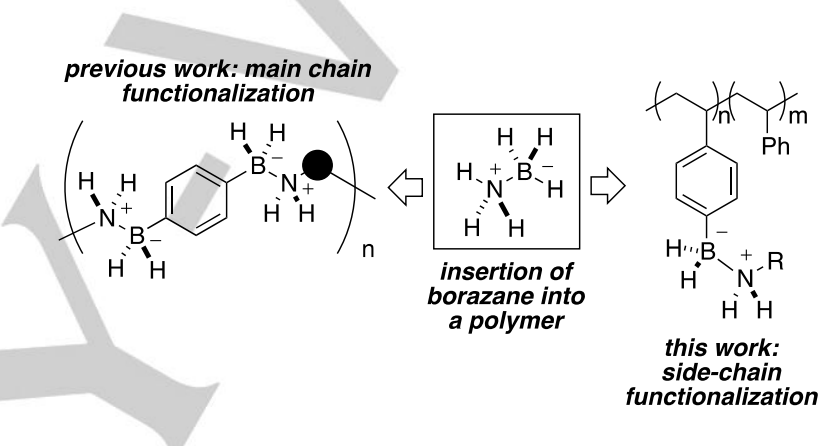

Figure 1. $\mathrm{H}_{2}$-rich Boron polymers.

The radical copolymerization of styrene with $p$-pinacolatoborylstyrene leads to almost statistical copolymers with increasing boron content (reactivity ratios close to 1 , see Figure 2 and $\mathrm{SI}$ part 3). The pinacol boronate groups on the side chains were reduced by lithium aluminum hydride in the presence of the mono-propyl, or mono-decyl ammonium salts in a THF/toluene mixture at $0^{\circ} \mathrm{C}$. This converted them into the corresponding mono-alkylamine-boranes in a one-pot post-functionalization step. The ${ }^{11} \mathrm{~B}$ NMR signals exhibited an upfield shift from $26.4 \mathrm{ppm}$ to $-13.9 \mathrm{ppm}$, in agreement with the $\mathrm{sp}^{2}$ to $\mathrm{sp}^{3}$ hybridization of the $\mathrm{B}$ atom. The toluene/THF mixture was best at allowing both a quantitative post-functionalization and an easy precipitation and separation of the salts produced by the reduction from the expected polymers.

The longer chain decylamine was chosen to improve the processability and solubility of the corresponding polystyrene- $g$ boramines. Conversely, the shorter propylamine was selected to maximize the amine-borane to carbon atoms ratio. In both cases, polymers with molar masses $>10^{5}$ Da were obtained. We reference the copolymers obtained as PS-BN-Cn-x\%, where $\mathrm{n}$ is 3 or 10 , depending on the amine, and $\mathrm{x}$ is the ratio of boron-containing monomer inserted into the polymer.

We used TPD to determine the dehydrogenation temperature for all the copolymers. At low boron content both PS-BN-C3-5\% and PS-BN-C10-5\% dehydrogenate at $\sim 153^{\circ} \mathrm{C}$. Conversely, the fully boronated polymers PS-BN-C3-100\% and PS-BN-C10$100 \%$ dehydrogenate at respectively $\sim 136^{\circ} \mathrm{C}$ and $\sim 150^{\circ} \mathrm{C}$ Interestingly, the thermal dehydrogenation in the solid state vs. 
boron content curve exhibited a non-linear, positive bell-shape profile (Figure 4). For the C3 derivatives, a maximum dehydrogenation temperature was observed at approx. $10 \%$ boron content, while it shifted at around $15 \%$ for the decylamine ones. In both cases, the maximum dehydrogenation temperature was $\sim 172^{\circ} \mathrm{C}$.
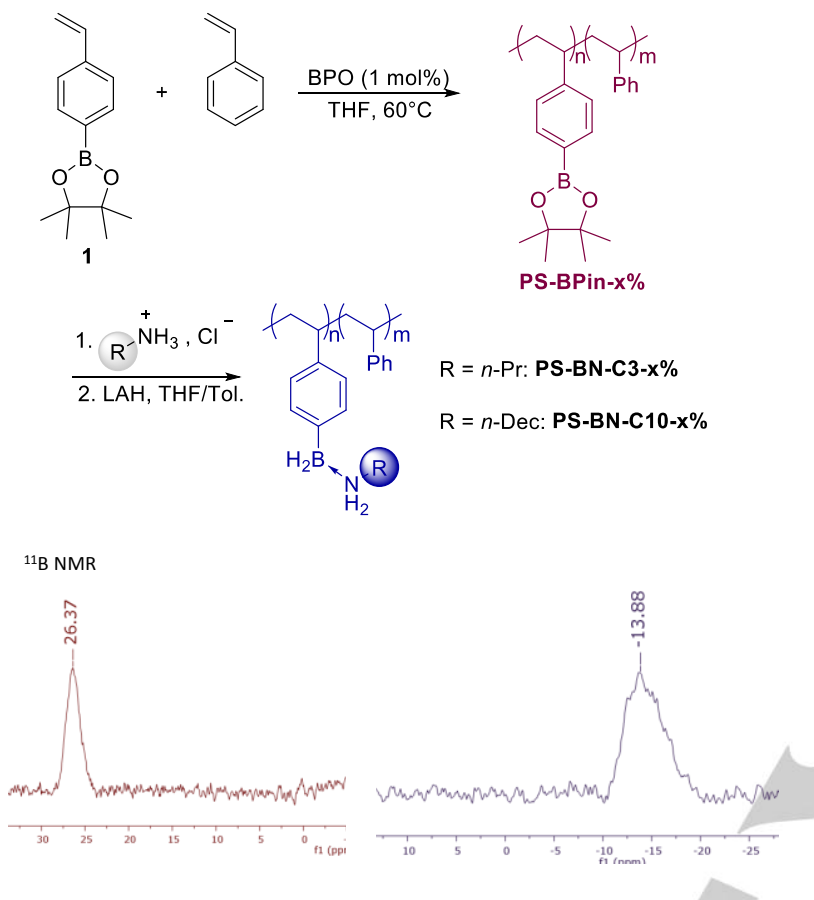

Figure 2. Top: Synthesis of polystyrene-g-boramines using free radical polymerization; Bottom: ${ }^{11} \mathrm{~B}$ NMR $\left(\mathrm{d}_{8}-\mathrm{THF}, 96 \mathrm{MHz}\right.$ ) of PS-BPin (left) and PSBN (right).

In both series, the dehydrogenation temperature is significantly higher than that of the corresponding molecular mimics of the polymer units $\left(\sim 145^{\circ} \mathrm{C}\right.$ for $n \mathrm{PrNH}_{2} \cdot \mathrm{BH}_{2} \mathrm{Ph}$ and $\sim 127^{\circ} \mathrm{C}$ for $n$ Dec $\mathrm{NH}_{2} \cdot \mathrm{BH}_{2} \mathrm{Ph}$ ), in stark contrast to the polymers featuring the amine-boranes in the main chain.[5a] The polymer environment therefore exerts a dominant influence over the temperature, presumably by preventing the dimeric arrangement required for the amino-borane dehydrogenations.[7]

The number of dimeric arrangements via dihydrogen bonds (DHBs) that can be formed between the amine-boranes grows with the boron content. This should result in an overall decrease of the dehydrogenation temperature with growing boron content (the more DHBs, the easier the dehydrogenation). Clearly this is what happens with the high boron content polymers.

At low amine-borane content however, the dehydrogenation temperature is also lower. To explain this, one has to consider that the polymer chains mobility also plays a role. For the DHBs to form in the bulk, the polystyrene- $g$-boramines chain must be mobile, ie they must display a glass transition temperature $\left(T_{g}\right)$ that is lower than the dehydrogenation temperatures. We thus resorted to DSC to assess the thermal behavior of the polystyrene- $g$-boramines.

To quantify and understand the differences between the two polymer series (C3 and $\mathrm{C} 10$ chains), we wished to study the variations in heat capacity or $\Delta \mathrm{CpT}_{\mathrm{g}}$ at glass transition. Unfortunately, the $\mathrm{T}_{\mathrm{g}}$ 's could not be determined directly on the polystyrene- $g$-boramines because their glass transition is concomitant with the dehydrogenation and the values of the respective heat capacities are therefore impossible to measure on the first heat. To circumvent this issue, we focused on the dehydrogenated polymers because we expected their $\Delta \mathrm{CpT}_{\mathrm{g}}$ values to provide us with an indirect measure of the mobility. Indeed, the DHBs that impact the glass transition likely lead to macromolecular chains-bridging covalent bonds upon dehydrogenation, therefore following the same trend as the initial polymers (which they "freeze").

The value of the glass transition heat capacity of PS-BN-C3-3\%DH (for de-hydrogenated) is close to that of polystyrene, with $\Delta \mathrm{Cp} \sim 0.2 \mathrm{~J} \cdot \mathrm{g}^{-1} \cdot \mathrm{K}^{-1}$. Beyond this ratio, the $\mathrm{T}_{\mathrm{g}}$ increased while the corresponding $\Delta \mathrm{Cp}$ rapidly decreased until the glass-transition phenomenon seemingly disappeared completely above $40 \%$ of amine-borane content (see SI, part 10). Thus, according to these DSC studies, dehydrogenated polymers PS-BN-C3-40\%DH and PS-BN-C3-100\%-DH are highly rigid materials, which exhibit no apparent glass transition.

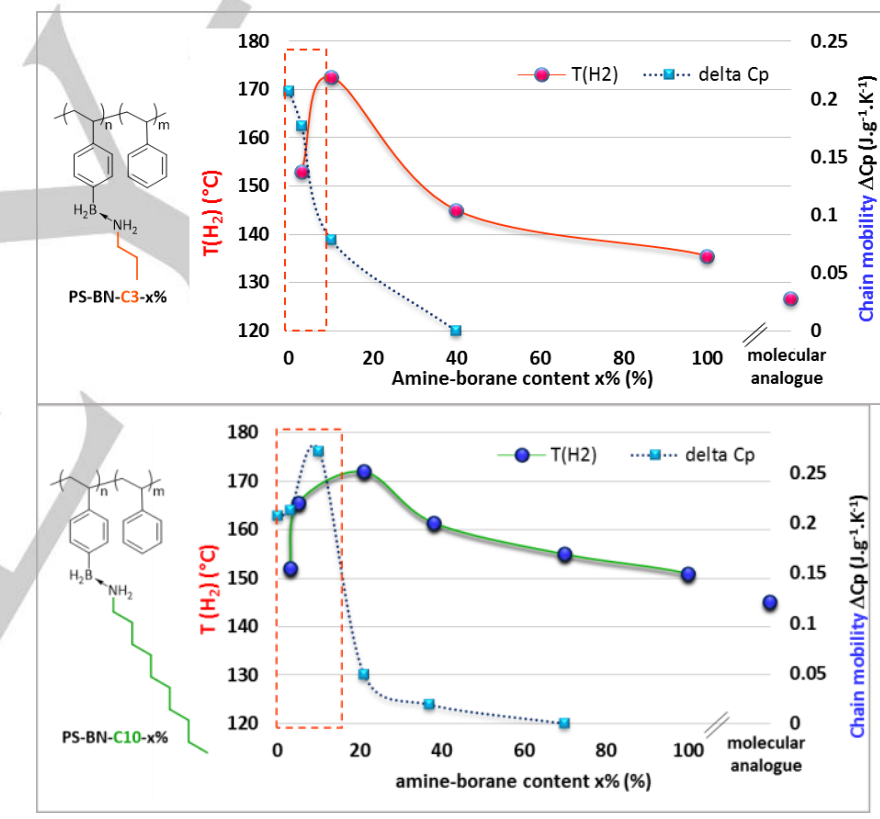

Figure 4. Top: Variation of the dehydrogenation temperature (dots) and $\Delta \mathrm{C}_{\mathrm{p}}$ (squares) as a function of the boron content in the PS-BN-C3 series; Variation of the dehydrogenation temperature (dots) and $\Delta \mathrm{C}_{p}$ (squares) as a function of the boron content in the PS-BN-C10 series.

Glass transitions have also been identified in the PS-BN-C10$\mathbf{x} \%$-DH polymers, until $70 \%$ of amine-borane functionalized content. This means that this family globally presents a higher chain mobility than its $\mathrm{C} 3$ parents. In contrast with the PS-BNC3-x\%-DH polymers, the heat capacity of PS-BN-C10-x\%-DH glass transitions increased from 0 to $10 \%$ decylamine-boranecontaining units. It appears that the plasticizing effect of the $\mathrm{C} 10$ aliphatic chains influences the glassy state, lowering the $T_{g}$, and prevails regardless of any potential interchain supramolecular interactions (and subsequent covalent bonds after 
dehydrogenation). Thus, the dehydrogenated polymers appear to be decent models to explain the dehydrogenation from a chain mobility perspective. Beyond $10 \%$ of amine-borane content, the heat capacity of glass transitions dramatically decreased.

Considering that the glass transition of a polymer is the physical indication of a rearrangement between macromolecules, whereby below the $T_{g}$ there is limited molecular mobility whereas above $T_{g}$ there is higher mobility, and much lower viscosity, it can be concluded that even if there are only a few amineboranes present at low $B$ ratio, it is enough to lower the dehydrogenation temperature because the bulk polymer is above $\mathrm{T}_{\mathrm{g}}$. It therefore can undergo the chain reorganization leading to the crucial supramolecular interactions required for dehydrogenation. When the starting polymer has lots of them to start with (i.e. at higher boron content), the chains become less mobile, as the polymer has established a stronger interchain network. $T_{g}$ increases or disappears, but because the network is installed, the dehydrogenation is still easier. Conversely, at medium boron content, not enough interactions are present, and the material is already too constrained to allow chain mobility, therefore the dehydrogenation temperature raises.

Having established that the polymer matrix has a controlling influence over the dehydrogenation of the amine-boranes on the side chains, we sought to increase the $\mathrm{H}_{2}$ content of the materials. Indeed, even the $100 \%$-functionalized polystyrenes- $g$ boramines contain only a moderate amount of $\mathrm{H}_{2}(2.1 \mathrm{wt} \%$ for PS-BN-C3-100\% and 1.4 wt $\%$ for PS-BN-C10-100\%). For comparison, borazane contains a (theoretical) maximum $19.6 \mathrm{wt} \%$ of $\mathrm{H}_{2}$, and our first generation polyboramines contained up to $4 \mathrm{wt} \% \mathrm{H}_{2}$.[5a] We aimed at improving the PSBN polymers performance by blending them with borazane $(A B),[8]$ in the hope that the physical mixture would retain processability and/or lead to cleaner $\mathrm{H}_{2}$ than pure $\mathbf{A B}$.

The new materials were obtained by dissolving from 0.5 to 5 equivalents of AB with PS-BN-C10-100\% in THF (Figure 5). The resulting clear solutions were then dried under high vacuum to yield [PS-BN-C10-100\%; y AB] as a colorless solid. The presence of $\mathbf{A B}$ was confirmed by IR spectroscopy by quantifying the increase of the amine-borane characteristic bands, such as the B-H stretching at $2320 \mathrm{~cm}^{-1}$ (see SI, part 8). Temperature-Programmed Desorption (TPD) experiments were performed (see $\mathrm{SI}$, part 12). AB loses $\mathrm{H}_{2}$ thermally in two stages, with release of a first equivalent at $\sim 125{ }^{\circ} \mathrm{C}$ and a second at $\sim 167{ }^{\circ} \mathrm{C}$ and PS-BN-C10-100\% releases two equivalents of $\mathrm{H}_{2}$ in a one-stage process peaking at $\sim 153^{\circ} \mathrm{C}$. The TPD traces of the AB-doped hybrid materials all exhibit a dehydrogenation curve with an onset at $80^{\circ} \mathrm{C}$, peaking near $120^{\circ} \mathrm{C}$ (e. g. $116^{\circ} \mathrm{C}$ for [PS-BN-C10-100\%; $5 \mathrm{AB}$ ]) and then slowly getting back to the baseline over a large range (until $220^{\circ} \mathrm{C}$ ). The traces are clearly not the superimposition of the traces of both pure precursor materials. The onset and peak dehydrogenation temperatures are lower in the mixed materials, suggesting a synergistic effect. Interestingly, the dehydrogenation curves of [PS-BN-C10-100\%; 1 to $5 \mathrm{AB}$ ] feature narrow peaks resembling the first dehydrogenation peak of $\mathbf{A B}$.
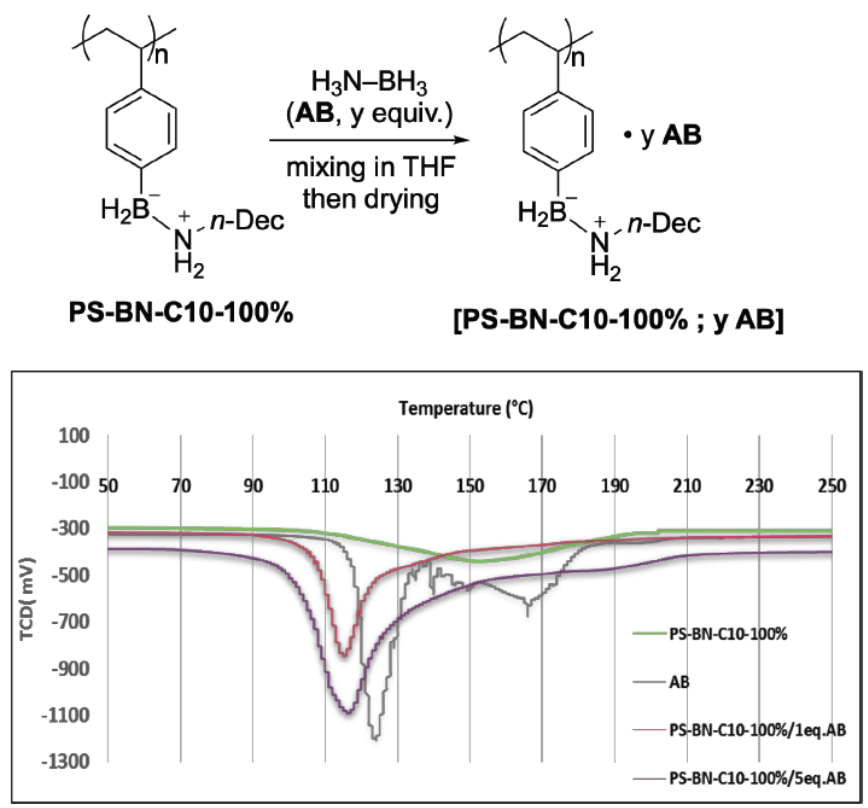

Figure 5. Synthesis (top) and dehydrogenation profiles (bottom) of hybrid materials obtained by mixing polystyrene- $g$-boramines and borazane.

We think that the borazane DHB network is substantially disrupted by the organic chains when $\mathbf{A B}$ is included within the polymer. This would result in a lower crystallinity of $\mathbf{A B}$ in the doped materials relative to that of pure $\mathbf{A B}$.[8b] At the same time, the boramines on the side-chains of the polymer may act as a template promoting "mixed" DHBs, which is why the dehydrogenation temperature of the hybrid is lower than that of both the polystyrene- $g$-boramine and AB. $[7,9]$

The hybrid material [PS-BN-C10-100\%; 5 AB] has a maximal $\mathrm{H}_{2}$ capacity close to $8 \mathrm{wt} \%$ and it dehydrogenates as a single entity. It thermally dehydrogenated at $116^{\circ} \mathrm{C}$, below either $\mathbf{A B}$ or the polystyrene-g-boramines taken separately. This suggests that the templating effect of the grafted polymer on $A B$ is maintained even for a significant excess of $\mathbf{A B}$. Above a 5:1 ratio, the hybrid materials started to exhibit deviations from their synergistic behavior.

Most interestingly, when the purity of $\mathrm{H}_{2}$ was assessed by TPD after switching the vectorizing gas from $\mathrm{Ar}$ to $\mathrm{H}_{2}$, we observed that the dihydrogen produced from the polystyrene-g-boramines and their corresponding hybrid materials was of higher purity (see SI, part 12). In contrast, the dihydrogen produced from AB was contaminated by multiple products, presumably boron- and nitrogen-containing volatiles. We think that the polymeric network plays two roles. First, the templating effect results in some of the by-products being anchored to the materials, resulting in a lowered production of volatile contaminants.[10] Second, the remaining volatile contaminants can be adsorbed more efficiently onto the polymer matrix.

To conclude, we have shown that the dehydrogenation temperature of hydrogen-rich amine-boranes can be controlled by their insertions into a polymer matrix, and not by modifying the electronics or sterics of the Lewis pair. This was achieved by 
embedding the amine-boranes into polymers. The boroncontaining monomer ratio controls the density of the DHBs that are at the root of the release of dihydrogen. The polymeric nature of the material affects how easily DHBs can be established. We also evidenced that the Boron-polymer with the highest boron content is an organo-catalyst for the dehydrogenation of ammonia-borane, likely because of a templating effect. Finally, all the polymer-containing and borazane-containing "hybrid" materials release a much cleaner dihydrogen than borazane alone, which should be of interest for all applications where a clean gas is needed.

\section{Acknowledgements}

We thank CNRS, CPE Lyon, Université Claude Bernard Lyon 1 and ANR (grant NHCX) for funding of this work. A. L. thanks UCBL for a Ph. D. stipend.

\section{Keywords: Boron • Polymers • Boranes • Lewis pairs •} Dehydrogenation

[1] A. Staubitz, A. P. M. Robertson, I. Manners Chem. Rev. 2010, 110, 4079-4124.

[2] a) Z. Mo, A. Rit, J. Campos, E. L. Kolychev, S. Aldridge, J. Am. Chem. Soc. 2016, 138, 3306-3309; b) A. Khalily, H. Eren, S. Akbayrak, H. H. Susapto, N. Biyikli, S. M. O. Guler, Angew. Chem. Int. Ed. 2016, 55 12257-12261; Angew. Chem. 2016, 128, 12445-12449; c) Z. Lu, L. Schweighauser, H. Hausmann, H. A. Wegner, Hermann A., Angew. Chem. Int. Ed. 2015, 54, 15556-15559; Angew. Chem. 2015, 127, 15777-15780; d) X. Hu, M. Soleilhavoup, M. Melaimi, J. Chu, G. Bertrand, Angew. Chem. Int. Ed. 2015, 54, 6008-6011; Angew. Chem. 2015, 127, 6106-6109; e) B. L. Conley, D. Guess, T. J. Williams J. Am. Chem. Soc. 2011, 133, 14212-14215; f) R. J. Keaton, J. M. Blacquiere, R. T. Baker, J. Am. Chem. Soc. 2007, 129, 1844-1845; g) M. C. Denney, V. Pons, T. J. Hebden, M. D. Heinekey, K. I Goldberg, J Am. Chem. Soc. 2006, 128, 12048-12049; for dehydrocouplings, see h) J. R. Vance, A. Schafer, A. P. M. Robertson, K. Lee, J. Turner, G. R Whittell, I. Manners, Ian, J. Am. Chem. Soc. 2014, 136, 3048-3064; i) R. T. Baker, J. C. Gordon, C. W. Hamilton, N. J. Henson, P.-H. Lin, S. Maguire, M. Murugesu, B. L. Scott, N. C. Smythe, J. Am. Chem. Soc. 2012, 134, 5598-5609; k) G. M. Adams, A. L. Colebatch, J. T. Skornia, A. I. McKay, H. C. Johnson, G. LloydJones, S. A. Macgregor, N. A. Beattie, A. S. Weller, J. Am. Chem. Soc. 2018, 140, 1481-1495. For reviews, see: I) A. Rossin, M. Peruzzini Chem. Rev. 2016, 116, 8848-
8872; m) A. L. Colebatch, A. S. Weller, Chem. Eur. J. 2019, 25, 13791390.

[3] a) F. H. Stephens, V. Pons, R. T. Baker Dalton Trans. 2007, 2613 2626; b) T. B. Marder, Angew. Chem. Int. Ed. 2007, 46, 8116-8118 Angew. Chem. 2007, 119, 8262-8264.

[4] a) G. Chen, L. N. Zakharov, M. E. Bowden, A. J. Karkamkar, S. M. Whittemore, E. B. Garner, T. C. Mikulas, D. A. Dixon, T. Autrey, S.-Y. Liu J. Am. Chem. Soc. 2015, 137, 134-137; b) W. Luo, P. G. Campbell, L. N. Zakharov, S.-Y. Liu, J. Am. Chem. Soc. 2011, 133, 19326-19329; c) A. Staubitz, M. Besora, N. J. Harvey, I. Manners, Inorg. Chem. 2008 47, 5910-5918.

[5] a) A. Ledoux, P. Larini, C. Boisson, V. Monteil, J. Raynaud, E. Lacôte, Angew. Chem. Int. Ed. 2015, 54, 15744-15749; Angew. Chem. 2015, 127, 15970-15975. For an application of the dehydrogenated polymers, see: b) T. Lorenz, M. Crumbach, T. Eckert, A. Lik, H. Helten, Angew. Chem. Int. Ed. 2017, 56, 2780-2784; Angew. Chem. 2017, 129, 2824-2828.

[6] We unsuccessfully attempted the direct free radical polymerization of the amine-borane substituted styrene (see SI for its synthesis). We believe this is due to simultaneous dehydrogenation and/or early termination due to $\mathrm{H}$-atom transfer from the monomer. For chainsubstituted Boron polymers with other properties, see: a) K. Parab, K Venkatasubbaiah, F. Jäkle J. Am. Chem. Soc. 2006, 128, 12879 12885; b) H. Kuhtz, F. Cheng, S. Schwedler, L. Böhling, A. Brockhinke, L. Weber, K. Parab, F. Jäkle ACS Macro Lett. 2012, 1, 555-559; c) K. Tanaka, K. Tamashima, A. Nagai, T. Okawa, Y. Chujo Macromolecules 2013, 46, 2969-2975; d) G. C. Welch, G. C. Bazan J. Am. Chem. Soc 2011, 133, 4632-4644; e) Y. Kotsuchibashi, R. V. C. Agustin, J.-Y. Lu, D. G. Hall, R. Narain ACS Macro Lett. 2013, 2, 260-264; f) F. Cheng, E. M. Bonder, F. Jäkle J. Am. Chem. Soc. 2013, 135, 17286-17289; i) W. Wan, F. Cheng, F. Jäkle Angew. Chem. Int. Ed. 2014, 53, 8934-8938 Angew. Chem. 2014, 126, 9080-9084; j) J. N. Cambre, D. Roy, S. R. Gondi, B. S. Sumerlin J. Am. Chem. Soc. 2007, 129, 10348-10349.

[7] a) M. Bowden, T. Autrey, Curr. Opin. Solid State Mater. Sci. 2011, 15, 73-79; b) J. Li, S. M. Kathmann, H.-S. Hu, G. K. Schenter, T. Autrey, M. Gutowski, Inorg. Chem. 2010, 49, 7710-7720.

[8] For use of other support materials, see: a) A. Rossin, G. Tuci, L. Luconi, G. Giambastiani, ACS Catal. 2017, 7, 5035-5045 (MOFs); b) J. Alipour, A. M. Shoushtari, A. Kaflou, J. Mater. Sci. 2015, 50, 3110-3117 (PMMA); c) M. Rueda, L. M. Sanz-Moral, J. J. Segovia, A. Martin, Microporous Mesoporous Mater. 2017, 237, 189-200 (silica); d) Z. Tang, X. Chen, H. Chen, L. Wu, X. Yu, Angew. Chem. Int. Ed. 2013, 52, 5832-5835; Angew. Chem. 2013, 125, 5944-5947 (graphitic nano carbons); e) S. Sepehri, A. Feaver, W. J. Shaw, C. J. Howard, Q. Zhang, T. Autrey, G. Cao, J. Phys. Chem. B 2007, 111, 14285-14289 (carbon cryogel).

[9] For a similar observation, see: S. S. Mal, Frances H. Stephens, R. T. Baker, Chem. Commun. 2011, 47, 2922-2924.

[10] Pictures of the materials and of borazane before and after dehydrogenation can be found in the SI (see visuals). One can clearly see that, as opposed to our materials, borazane catastrophically expands by foaming upon thermal dehydrogenation. 
Entry for the Table of Contents (Please choose one layout)

Layout 1:

\section{COMMUNICATION}

Grafting of Hydrogen-rich amineborane Lewis pairs in polymeric scaffolds leads to materials releasing $\mathrm{H}_{2}$ at a temperature controlled by the boron ratio and the macromolecular properties, and not by electronic effects. The materials also catalyze the dehydrogenation of borazane.

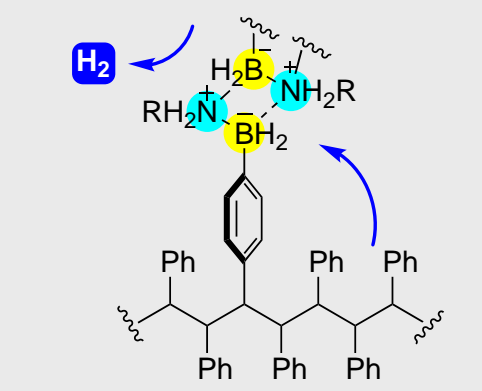

Boron ratio in polymer chain controls probability of dimer formation
Audrey Ledoux, Jean Raynaud, * Emmanuel Lacôte*

Page No. - Page No.

Tunable hydrogen release from amine-boranes via their insertion into functional polystyrenes 